\title{
CD44-Tropic Polymeric Nanocarrier for Breast Cancer Targeted Rapamycin Chemotherapy
}

\author{
Yunqi Zhao, MS, \\ Department of Pharmaceutical Chemistry, The University of Kansas, 2095 Constant Ave. \\ Lawrence, Kansas 66047, United States \\ Ti Zhang, MS, \\ Department of Pharmaceutical Chemistry, The University of Kansas, 2095 Constant Ave. \\ Lawrence, Kansas 66047, United States \\ Shaofeng Duan, PhD, \\ Department of Pharmaceutical Chemistry, The University of Kansas, 2095 Constant Ave. \\ Lawrence, Kansas 66047, United States
}

Neal M. Davies, PhD, and Faculty of Pharmacy, The University of Manitoba, 750 McDermot Road, Winnipeg, Manitoba R3Y 2N2, Canada

\author{
M. Laird Forrest, PhD* \\ Department of Pharmaceutical Chemistry, The University of Kansas, 2095 Constant Ave. \\ Lawrence, Kansas 66047, United States
}

\begin{abstract}
In contrast with the conventional targeting of nanoparticles to cancer cells with antibody or peptide conjugates, a hyaluronic acid (HA) matrix nanoparticle with intrinsic-CD44-tropism was developed to deliver rapamycin for localized CD44-positive breast cancer treatment. Rapamycin was chemically conjugated to the particle surface via a novel sustained-release linker, 3-amino-4methoxy-benzoic acid. The release of the drug from the HA nanoparticle was improved by 42 -fold compared to HA-temsirolimus in buffered saline. In CD44 positive MDA-MB-468 cells, using HA as drug delivery carrier, the cell-viability was significantly decreased compared to free rapamycin and CD44-blocked controls. Rat pharmacokinetics showed that the area-under-thecurve of HA nanoparticle formulation was 2.96-fold greater than that of the free drug, and the concomitant total body clearance was 8.82-fold slower. Moreover, in immunocompetent BALB/c
\end{abstract}

\footnotetext{
(C) 2014 Elsevier Inc. All rights reserved.

*Correspondence to: Dr. M. Laird Forrest, The University of Kansas, 2095 Constant Ave., Lawrence, KS 66047. Ph.: 1-785-864-4388. mforrest@ku.edu. Fax: 1-785-864-5736. TZ and SD contributed equally to this study.

Publisher's Disclaimer: This is a PDF file of an unedited manuscript that has been accepted for publication. As a service to our customers we are providing this early version of the manuscript. The manuscript will undergo copyediting, typesetting, and review of the resulting proof before it is published in its final citable form. Please note that during the production process errors may be discovered which could affect the content, and all legal disclaimers that apply to the journal pertain.

Financial Conflict of Interest

MLF has a financial interest in HylaPharm LLC, which has licensed related technologies.
} 
mice bearing CD44-positive 4T1.2neu breast cancer, the rapamycin1loaded HA particles significantly improved animal survival, suppressed tumor growth and reduced the prevalence of lung metastasis.

\section{Keywords}

Hyaluronic acid; Rapamycin; CD44; Breast Cancer

\section{Introduction}

Hyaluronic acid (HA) is a highly water soluble and biodegradable polymer that distributed throughout human body. It is one of the principal ligands for CD44. CD44 is a cell surface molecule involved in proliferation, differentiation and migration of cancer cells (1). The CD44 receptor is one of the most widely accepted cell surface markers of variety types of cancer cells, such as breast cancer cell lines MCF-7, MDA-MB-468 and MDA-MB-231 (2). The expression of specific CD44 isoforms is also associated with various cancer biomarkers and tumor subtypes (3). The CD44 receptor mediates cell-cell and cell-matrix interactions through its affinity with HA and the adhesion with HA molecule plays an important role in tumor growth and progression. Therefore, the interaction of CD44 and HA can be used as a potential target for cancer therapy (4-7).

The usage of HA as a drug delivery platform matrix could provide specific cancer targeting via CD44 interaction and the benefits associated with both active-targeting nanoparticle and polymer-drug conjugates. Biodegradable polymeric nanoparticles with the combination of targeted delivery and controlled release manner could allow drug to be specifically delivered to cancer cells per targeting bio-recognition event and minimize systemic toxicity (8). A steady state cytotoxic drug concentration at the tumor site over an extended period of time can be reached by this strategy. One the other hand, the polymer-drug conjugates are designed to increase therapeutic index by drug specific targeting of disease, tissues, reducing systemic drug exposure $(9,10)$, and increased plasma circulation time. The polymer-drug conjugates can be bio-activated to provide their own therapeutic benefits, and they also can improve release kinetics of the drug and prevent carrier accumulation in the body (11). Moreover, the polymer based drug delivery platform has demonstrated prolonged in vivo half-life, is less prone to enzyme degradation with less immunogenicity compared to the conventional chemotherapy (12-14). It also provides an effective and promising way for neoplastic treatment due to the changing of cellular uptake mechanisms, pharmacokinetic disposition and ultimately targeting of the drug (15).

Rapamycin is a selective inhibitor of mammalian target of rapamycin (mTOR) and blocks the subsequent activation of p70 S6 kinase (16). The mTOR pathway regulates a variety of cellular signals and development processes, including mitogenic growth factors, hormones, nutrients, cellular energy levels and stress conditions (17). It is frequently activated in certain human cancers, such as breast cancer (18). The mTOR pathway is also widely involved in both apoptotic and autophagic pathways during oxidative stress $(19,20)$. Therefore, inhibiting the mTOR pathway is extensively considered as an effective approach 
for targeted cancer therapy (21). One of the challenges of using rapamycin as an anticancer agent in clinic is due to its lipophilic chemistry (22). By using HA a drug delivery carrier, the solubility of rapamycin in water can be dramatically increased from $2.6 \mu \mathrm{g} / \mathrm{mL}$ to more than $10 \mathrm{mg} / \mathrm{mL}$.

In this study, rapamycin loaded HA nanoparticles were prepared. Sustained and controlled release of the drug was achieved. Both chemical and physical properties of the drug loaded nanoparticle were fully characterized. In vitro studies were performed to examine CD44mediated cancer cell uptake. Efficacy of the drug conjugate was evaluated in BALB/c mice and pharmacokinetics studies were completed in Sprague-Dawley rats.

\section{Methods}

Materials

$\mathrm{HA}_{35 \mathrm{k}}$ and rapamycin were purchased from Lifecore Biomedical, Inc. (Chaska, MN) and LC Laboratories (Woburn, MA), respectively. Fmoc-3-amino-4-methoxy-benzoic acid was purchased from AnaSpec, Inc. (Fremont, CA). Other materials and solvents, of their highest grade, were purchased from Fisher Scientific (Lenexa, KS) or Sigma Aldrich (St. Louis, $\mathrm{MO})$.

\section{Synthesis of rapamycin 42-hemisuccinate}

The synthetic scheme is shown in Figure 1A. A mixture of rapamycin $(0.20 \mathrm{~g}, 0.22 \mathrm{mmol})$, succinic anhydride $(0.10 \mathrm{~g}, 1.0 \mathrm{mmol})$ and Novozym SP $435(0.45 \mathrm{~g})$ in toluene $(10 \mathrm{~mL})$ was stirred at $45^{\circ} \mathrm{C}$ under argon for $40 \mathrm{~h}$. The enzyme was filtered off and washed with toluene, and the combined organic phases were concentrated under reduced pressure. The residue was purified by silica gel column chromatography and eluted with EtOAc-hexane (1:4) to furnish the title compound as a white solid $(0.2 \mathrm{~g}, 90 \%)(23)$.

\section{Synthesis of HA-Temsirolimus}

The 42-hemisuccinated rapamycin $(0.150 \mathrm{~g}, 0.15 \mathrm{mmol})$ was dissolved in $4 \mathrm{~mL}$ of dimethyl sulfoxide (DMSO), and 1-ethyl-3-(3-dimethylaminopropyl) carbodiimide hydrochloride $(\mathrm{EDC} \cdot \mathrm{HCl})(0.057 \mathrm{~g}, 0.30 \mathrm{mmol})$ and 1-hydrocybenzotriazole hydrate $\left(\mathrm{HOBt} \cdot \mathrm{H}_{2} \mathrm{O}\right)(0.046$ $\mathrm{g}, 0.30 \mathrm{mmol}$ ) were added to the solution. After $20 \mathrm{~min}$, this solution was added drop wise to HA-adipic acid dihydrazide (ADH) $(0.120 \mathrm{~g}, 22 \% \mathrm{ADH})$ in $10 \mathrm{~mL}$ of double distilled water $\left(\mathrm{ddH}_{2} \mathrm{O}\right)$ cooled on ice. HA-ADH was synthesized as previously described (23). After the addition, the mixture was stirred at ambient temperature $\left(\mathrm{ca} .20^{\circ} \mathrm{C}\right)$ overnight. Then, the solution was poured into $100 \mathrm{~mL}$ of $95 \%$ ethanol (EtOH), and the white precipitate was collected by centrifugation. This procedure was repeated another two times. The collected solid was dried under vacuum overnight and $0.085 \mathrm{~g}$ of the product was obtained (yield: $31.48 \%$ ). The structure was verified by ${ }^{1} \mathrm{H}-\mathrm{NMR}$ (supplementary data).

\section{Synthesis of HA-Rapamycin-42-(3'-amino-4'-methoxy)benzoate (HA-L-Rapamycin)}

The synthetic scheme of HA-L-rapamycin is shown in Figure 1B. 
Five milliliters of oxalyl chloride in dry methylene chloride (2.0 M in DCM) was added to $150 \mathrm{mg}$ of Fmoc-3-amino-4-methoxy-benzoic acid along with one drop of dry dimethylformamide (DMF) as a catalyst. The mixture was stirred at ambient temperature (ca. $22^{\circ} \mathrm{C}$ ) under dry argon for $2 \mathrm{~h}$. The white suspension turned into a light yellow, clear solution as the reaction neared completion. The organic solvent was removed under reduced pressure.

Compound 1 was suspended in $5 \mathrm{~mL}$ of dry DCM and $100 \mathrm{mg}$ of rapamycin and $200 \mathrm{mg}$ of $\mathrm{NaHCO}_{3}$ were added to the solution. The mixture was stirred at ambient temperature for $2 \mathrm{~h}$ under dry argon and protected from light. The suspension was filtered, and the filtrate was washed with bicarbonate water and brine. The organic solvent was dried with $\mathrm{Na}_{2} \mathrm{SO}_{4}$ and then removed under reduced pressure.

Compound 2 was suspended in $20 \%$ (v/v) piperidine in DMF. The solution was stirred at ambient temperature for $1 \mathrm{~h}$. The organic solvent was removed under reduced pressure and the pale yellow solid was washed several times with $\mathrm{ddH}_{2} \mathrm{O}$.

$O$-(7-azabenzotriazol-1-yl)- $N, N, N^{\prime}, N^{\prime}$-tetramethyluronium hexafluorophosphate (HATU) (100 mg, $0.26 \mathrm{mmol})$ in $1 \mathrm{~mL}$ of DMF and N,N-Diisopropylethylamine (DIPEA) $(47 \mu \mathrm{L}$, $0.27 \mathrm{mmol}$ ) were added to $100 \mathrm{mg} \mathrm{HA}$ in $5 \mathrm{~mL}$ of $\mathrm{ddH}_{2} \mathrm{O}$. After $30 \mathrm{~min}$, rapamycin-42-(3'amino-4'-methoxy) benzoate in $5 \mathrm{~mL}$ of DMF was added. The mixture was stirred at ambient temperature overnight. Then, the organic solvent was removed by dialysis (10k MWCO snake skin pleated dialysis tubing, Thermo Scientific, Rockford, IL) against $\mathrm{ddH}_{2} \mathrm{O}$. The unbound drug produced a light yellow precipitate that was removed by centrifugation. The drug conjugate was further purified by tangential flow filtration (TFF) using a MicroKros mPEG filter (3.5k MWCO, Spectrum Labs, Rancho Dominguez, CA). The rapamycin loading degree on HA was determined by ${ }^{1} \mathrm{H}-\mathrm{NMR}$ (supplementary data).

\section{In Vitro Drug Release Study}

The in vitro release of the rapamycin from HA-drug conjugates into PBS or PBS supplemented with $10 \%$ fetal bovine serum (FBS) at $37{ }^{\circ} \mathrm{C}$ was monitored by a dialysis method using a SnakeSkin ${ }^{\circledR}$ pleated dialysis tubing (3,500 MWCO) (24). To prevent bacteria growth, $0.05 \%$ sodium azide was added to the serum release medium, and the medium was changed several times a day to maintain sink conditions. After the predetermined time intervals, samples were withdrawn from the dialysis tubing and analyzed using a Spectra MaxM2 microplate spectrophotometer with UV detection of rapamycin at $260 \mathrm{~nm}$.

\section{HA-Rapamycin Conjugate Characterization}

Particle Size-HA and HA-L-Rapa with different loading degrees were dissolved in PBS at the concentration of $2.5 \mathrm{mg} / \mathrm{mL}$. The particle sizes were measured with a ZetaPALS (Brookhaven Instruments Corp.) using the intensity weighted Gaussian distribution.

Zeta Potential-HA and HA-L-Rapa with different loading degree were dissolved in 10 $\mathrm{mM} \mathrm{KCl}$ at the concentration of $2.5 \mathrm{mg} / \mathrm{mL}$. Zeta potentials were measured using 
ZetaPALS. Zeta potential was calculated from the mobility of the system fitted into the Smoluchowski model (25).

Thermal Analysis-Differential scanning calorimetry (DSC) of HA-L-Rapa with different loading degrees and $\mathrm{HA}_{35 \mathrm{k}}$ polymer, as received, were studied using a Q100 Universal V4.3A DSC (TA Instruments, New Castle, Delaware). The samples were sealed in a standard aluminum pan and heated from 40 to $300{ }^{\circ} \mathrm{C}$ at a scan rate of $10^{\circ} \mathrm{C} / \mathrm{min}$.

Thermo gravimetric analysis (TGA) was performed on a Q50 thermogravimetric analyzer from TA Instruments. Samples were loaded on a platinum sample pan and heated from 25 to $300{ }^{\circ} \mathrm{C}$ with a heating rate of $10^{\circ} \mathrm{C} / \mathrm{min}$. Data were analyzed using Universal Analysis 2000 (version 4.3A) software (TA Instrument).

\section{Flow Cytometry Analysis}

The expression of CD44 receptor on the surface of breast cancer cells, MDA-MB-468 and 4T1.2neu, was examined by flow cytometry analysis. PE mouse anti-human CD44 (BD Pharmingen, San Jose, CA) was used to stain MDA-MB-468 cells, and PE rat anti-mouse CD44 (Pgp-1-R-PE, Southern Biothech, Birmingham, AL) was used with murine 4T1.2neu cells. PE mouse IgGI isotope control (BD Pharmingen, San Jose, CA) was used as a control. Anti-human CD44 antibody (H-CAM, Thermo Scientific, Rockford, IL) was used in receptor blocking assays.

\section{Cytotoxicity Assay}

Breast cancer MDA-MB-468 cells were maintained in Dulbecco's modified eagle medium supplemented with $10 \%$ fetal bovine serum (Hyclone Laboratory Inc., Logan, Utah). Cells were plated in white 96-well flat-bottomed plates at the concentration of 5,000 cells/well in $90 \mu \mathrm{L}$ of growth medium. After $12 \mathrm{~h}$, rapamycin or HA-L-Rapa in Hanks' solution were added at different concentrations. Hanks' solution and $10 \%$ trichloroacetic acid (TCA) were used as negative and positive control, respectively. The medium was refreshed $8 \mathrm{~h}$ after treatment. After $72 \mathrm{~h}$ post-treatment, resazurin blue $(5 \mu \mathrm{M})$ was added and the resorufin product was measured with a fluorophotometer using an excitation wavelength of $550 \mathrm{~nm}$ and an emission wavelength of $590 \mathrm{~nm}$.

\section{Cellular Uptake Study}

Breast cancer cells, MDA-MB-468, were seeded in a 12-well plate at the concentration of 50,000 cells/well in $1 \mathrm{~mL}$ of growth medium. After $12 \mathrm{~h}$ incubation, $10 \mu \mathrm{L}$ of human antiCD44 antibody was added to each well. After $1 \mathrm{~h}, 10 \mu \mathrm{M}$ of rapamycin or HA-L-Rapa conjugate were added to the cells. The supernatant was then analyzed by HPLC with a reverse phase column (TSK-GEL $\AA$ ODS-100Z, Tosoh Bioscience) at $50^{\circ} \mathrm{C}$ and UV detection at $278 \mathrm{~nm}$ for rapamycin.

\section{Pharmacokinetics Study}

Female Sprague-Dawley rats (350 - $450 \mathrm{~g}$, Charles Rivers) were administered rapamycin (1 $\mathrm{mg} / \mathrm{mL}$ in formulation buffer) by intraperitoneal (i.p.) injection or HA-L-Rapa (10 mg/kg equivalent rapamycin; $n=3$ for each group) by subcutaneous (s.c) injection under isoflurane 
anesthesia. Whole blood was withdrawn $(100 \mu \mathrm{L})$ from the tail vein at $0 \mathrm{~min}, 5 \mathrm{~min}, 30 \mathrm{~min}$, $1 \mathrm{~h}, 2 \mathrm{~h}, 4 \mathrm{~h}, 6 \mathrm{~h}, 12 \mathrm{~h}, 24 \mathrm{~h}$ and $48 \mathrm{~h}$ after dosing and placed in heparinized tubes (BD Vacutainer® Lithium Heparin 37 USP unit, BD Franklin Lakes, NJ). The whole blood was centrifuged at $15,000 \times \mathrm{g}$ for $10 \mathrm{~min}$, and the plasma was frozen at $-80^{\circ} \mathrm{C}$ until analyzed. The animal use statement was approved by the University of Kansas Institutional Animal Care and Use Committee. Plasma samples and stander curves were prepared using a procedure reported previously (26).

\section{Animal Survival Study and Tissue Distribution}

The murine breast cancer 4T1.2neu cell line was used to establish the synergetic orthotropic tumor model in immunocompetent mice. Female BALB/c mice (20 - $25 \mathrm{~g}$, Charles Rivers) under isoflurane anesthesia were inoculated in the right mammary gland with $1 \times 10^{6}$ cells suspended in PBS. Treatment started when the tumor size reached $50 \mathrm{~mm}^{3}$. Free rapamycin was dissolved in anhydrous ethanol and reconstituted in formulation buffer before use. The formulation buffer of free rapamycin consisted of $5 \%$ polyethylene glycol 400 and $5 \%$ Tween 80 in Hanks' balance salt solution. HA-L-Rapa was dissolved in Hanks' solution. Mice received $10 \mathrm{mg} / \mathrm{kg}$ equivalent rapamycin once per week for 3 weeks by i.p. injection (free rapamycin) or s.c injection (HA-L-Rapa). Control animals were injected with Hanks' solution. Animals were sacrificed when tumors grow larger than $1000 \mathrm{~mm}^{3}$ or if the tumors ulcerated in accordance with the approved animal use protocol.

Drug tissue distribution was determined in female BALB/c mice $(n=5)$. Tissue samples (50 $\mathrm{mg}$ ) in $500 \mu \mathrm{L}$ PBS were homogenized using a Tissue Tearor (BioSpec Products, Inc., Bartlvesville, OK). The homogenized tissue was mixed with $250 \mu \mathrm{L} \mathrm{ZnSO}_{4}$ and $500 \mu \mathrm{L}$ methanol. The mixture solution was centrifuged and the supernatant was analyzed by LC/MS.

In the tissue distribution study, BLAB/c mice were administered the drugs $12 \mathrm{~h}$ before being euthanized. Major organs (liver, kidneys, hear, spleen, lungs, brain, muscle), tumor and lymph nodes were excised and lightly washed with PBS. The organs were stored at $-80^{\circ} \mathrm{C}$ until analyzed by LC/MS.

\section{Statistical Analysis}

GraphPad Prism 5 software was used for statistical analysis. A $t$-test was used for statistical analysis of comparing two means. The Mantel-Cox test was used for comparison of KaplanMeyer analysis. In all comparisons, statistical significance was set at $p \leq 0.05$.

\section{Results}

\section{In Vitro Drug Release Study}

The release profiles of free rapamycin, HA-Temsirolimus and HA-L-Rapa were fitted using first order kinetics. The release half-lives of free rapamycin (PBS), HA-Temsirolimus (PBS), HA-L-Rapa (PBS), HA-L-Rapa (Serum) were $0.16 \mathrm{~h}, 4 \mathrm{~h}, 7 \mathrm{~d}$ and $1.5 \mathrm{~d}$, respectively. The rate constants of release were $0.01567 \mathrm{~h}^{-1}, 0.07881 \mathrm{~h}^{-1}, 0.01767 \mathrm{~h}^{-1}$ and $0.00344 \mathrm{~h}^{-1}$ 
for free rapamycin (PBS), HA-Temsirolimus (PBS), HA-L-Rapa (PBS) and HA-L-Rapa (serum), respectively.

\section{Characterizations of HA Drug Conjugates}

Particle sizes and Zeta potentials-Particle sizes of non-conjugated $\mathrm{HA}_{35 \mathrm{k}}$ and HA-LRapa with different drug loading degrees were shown in Table 1. There was no significant size difference between drug conjugated and non-conjugated HA. However, the absolute value of zeta potential decreased with increasing the drug loading degree on the HA. The negative zeta potential is expected as each HA monomer has one carboxylic group (pKa $\sim 4.5$ ) and one $\mathrm{HA}_{35 \mathrm{k}}$ has approximately 87 repeating units that yield a strong negatively charged nanoparticle at $\mathrm{pH}$ 7.4. By conjugating with rapamycin, a large hydrophobic molecule, carboxylic groups on HA surface were partially esterified by conjugation and some adjacent negative charged carboxylic groups were shielded by the drug; therefore, the absolute zeta potential value was decreased.

\section{Thermal Analysis}

DSC-Thermally induced conformational transitions of rapamycin, $\mathrm{HA}_{35 \mathrm{k}}$ and HA-L-Rapa with different drug loading degree are shown in Figure 2A. The rapamycin showed two endothermic peaks at $187^{\circ} \mathrm{C}$ and $200{ }^{\circ} \mathrm{C}$. The free $\mathrm{HA}_{35 \mathrm{k}}$ was characterized by a broad endothermic at $120{ }^{\circ} \mathrm{C}$ and an exothermic peak at $240{ }^{\circ} \mathrm{C}$. The first broad endothermic peak of $\mathrm{HA}$ at approximately $120^{\circ} \mathrm{C}$ suggests a dehydration process. An exothermic peak at ca. $240{ }^{\circ} \mathrm{C}$ was attributed to the decomposition of the polymer. The free rapamycin was characterized by two endothermic peaks at $187^{\circ} \mathrm{C}$ and $200{ }^{\circ} \mathrm{C}$. The split peak indicated that there are two crystalline structures of pure rapamycin. However, the second exothermic characteristic peak of $\mathrm{HA}_{35 \mathrm{k}}$ was not observed in HA-L-Rapa conjugates' DSC profiles. In addition, the two endothermic peaks of free rapamycin merged together and shifted to a higher temperature $\left(210^{\circ} \mathrm{C}\right)$.

Both the characteristic decomposition DSC peaks of $\mathrm{HA}_{35 \mathrm{k}}$ and rapamycin disappeared in the HA-L-Rapa profile. The exothermic peak of HA was ascribed to the melting of the polymer crystal. The disappearance of this peak indicated that the transition of HA from amorphous solid to crystalline solid was disappeared. In addition, the dehydration peak of HA shifted to a lower temperature (around $100^{\circ} \mathrm{C}$ ), indicating that the interaction between water and polymer decreased with conjugation of the hydrophobic rapamycin. The endothermic peak of rapamycin shifted to a higher temperature (near $210^{\circ} \mathrm{C}$ ). The enthalpy $(\Delta \mathrm{H})$ was calculated by integrating over the endothermic peak area. For $1.14 \%, 2.21 \%$ and $4.78 \%(\mathrm{w} / \mathrm{w})$ drug loaded $\mathrm{HA}$, the $\Delta \mathrm{H}$ was $33.6 \pm 0.95,53.58 \pm 0.83$ and $65.96 \pm 2.81 \mathrm{~J} / \mathrm{g}$, respectively. This demonstrated that the degree of thermal stability of HA-L-Rapa decreased with increased drug loading degree.

TGA-Thermogravimetric analysis showed that the drug-polymer conjugates were stable up to $200{ }^{\circ} \mathrm{C}$, when degradation began (Figure $2 \mathrm{~B}$ ). There were two transition regions during the decomposition process. For the non-drug conjugated HA, the $6.402 \%$ weight lost at approximately $100{ }^{\circ} \mathrm{C}$ was consistent with the expected water content of HA. The maximum decomposition, $72.24 \% \mathrm{wt}$, occurred at $235.72{ }^{\circ} \mathrm{C}$ which is consistent with polymer 
decomposition. The temperature of maximum degradation decreased with increasing drug loading: $224.14{ }^{\circ} \mathrm{C}$ for the $1.14 \%(\mathrm{w} / \mathrm{w})$ conjugate, $218.35^{\circ} \mathrm{C}$ for the $2.2 \%(\mathrm{w} / \mathrm{w})$ conjugate, and 216.61 for the $4.78 \%(\mathrm{w} / \mathrm{w})$ conjugate. The first transition region corresponds to the loss of water bonded to the HA molecule. The degradation temperatures of HA-L-Rapa conjugates were lower and the weight losses were smaller compared to $\mathrm{HA}_{35 \mathrm{k}}$. This trend is consistent with the DSC data, and it can be explained by that the water content was decreased when the hydrophobic molecules were conjugated on the HA surface. The second transition region is polymer degradation. The TGA plots illustrated that the weight loss was decreased with higher drug conjugated HA. This is also consistent with DSC data that the enthalpy at this region was increased with the drug loading degree.

\section{Flow Cytometry}

The expression of CD44 receptors on MDA-MB-468 cells was studied by flow cytometry. The cells were directly stained with PE-CD44 antibody and the PE-IgG1 isotope was used as a control (Figure 3). Protein quantification by flow cytometry demonstrated that the percentage of CD44 positive cells in MDA-MB-468 and 4T1.2neu was $99.92 \%$ and 89.59 $\%$, respectively. When MDA-MB-468 CD44 binding sites were blocked with H-CAM, the percentage of active sites decreased to $0.57 \%$. This result indicated that H-CAM can be used as an inhibitor to block the receptor-mediated endocytosis of HA.

\section{In Vitro Efficacy Study}

Cytotoxicity of unconjugated rapamycin and HA-L-Rapa at different concentrations was determined in MDA-MB-468 cells with or without H-CAM treatment (Figure 4). In CD44 positive MDA-MB-468 cells, HA-L-Rapa decreased cell-viability by $8.72 \%$ compared to rapamycin $(p=0.027)$ at $10 \mu \mathrm{M}$. The addition of H-CAM blocked CD44-mediated uptake and there was no significant difference in cell viability between HA-L-Rapa and the free $\operatorname{drug}(p=0.065)$.

Cellular Uptake Analysis MDA-MB-468 cells with or without H-CAM in a 12-well plate were treated with free rapamycin or HA-L-Rapa at a drug concentration of $10 \mu \mathrm{M}$. Drug concentration in the cell culture medium was analyzed by HPLC. In CD44 positive cells, the polymer drug conjugate significantly improved the drug uptake by 3.2 times compared to the free rapamycin $(p=0.012)$. When CD44 was blocked with H-CAM, there was no difference in rapamycin uptake between the free drug and polymer conjugate groups ( $p=$ $0.13)$.

\section{Pharmacokinetics Evaluation}

The pharmacokinetics of free rapamycin (i.p.) and HA-L-Rapa (s.c.) were compared in female Sprague-Dawley rats $(\mathrm{n}=3)$. A two-compartment pharmacokinetic model was selected to describe the exponential nature of the pharmacokinetics disposition of the drug (Figure 5). The area under the plasma concentration time curve $\left(\mathrm{AUC}_{0 \rightarrow \infty}\right)$ of rats administrated with HA-L-Rapa was 2.78-fold greater than that of the free drug, and the concomitant total body clearance was 2.09 -fold slower (Table 2). 


\section{Animal Survival and Tumor Suppression Studies}

$\mathrm{BALB} / \mathrm{c}$ mice were inoculated with $4 \mathrm{~T} 1$.2neu cells to evaluate the attenuation effect of HAL-Rapa on overall tumor progression. The median survival times of control, free rapamycin and HA-L-Rapa treatment groups were 17, 15 and 22 days, respectively (Figure 6A). Regression analysis demonstrated that HA-L-Rapa treatment was associated with significantly longer survival of mice with mouse mammary carcinoma compared with both the untreated control group $(p=0.047)$ and free drug treatment group $(p=0.018)$.

The in vivo 4T1.2neu breast cancer model also illustrated a significant decrease $(p=0.049)$ in tumor volume on day 20 in BALB/c mice treated with HA-L-Rapa $(10 \mathrm{mg} / \mathrm{kg}$ equivalent rapamycin) compared with that of the control group. Free rapamycin $(10 \mathrm{mg} / \mathrm{kg})$ also decreased tumor volume; however, the difference was not significant $(p=0.056)$.

\section{Tissue Distribution}

Twelve hours after s.c injection of HA-L-Rapa, the drug concentrations in tumor, lymph and lung were 1.56, 2.78 and 3.23-fold greater than the free drug treatment group (Table 3). The order of drug concentrations for the control group, free rapamycin (i.p.), were tumor $>$ lymph $>$ lungs $>$ kidneys $>$ heart $>$ liver $>$ muscle $>$ spleen $>$ brain. The drug concentration of HA-L-Rapa (s.c.) formulation were lungs $>$ lymph $>$ tumor $>$ spleen $>$ muscle $>$ liver $>$ kidneys $>$ heart $>$ brain.

\section{Discussion}

In this study, we described the use of HA as a drug delivery carrier that can enhance the efficacy of the conjugated rapamycin against CD44 positive cancer cells. Previously in our lab, we showed that the $t_{50 \%}$ of the lymphatic drainage of medium length HA (35 kDa -74 $\mathrm{kDa}$ ) to the axillary lymph node was $15-17 \mathrm{~h}$ and the $\mathrm{t}_{\max }$ was around $2 \mathrm{~h}(27)$. The release half-life of rapamycin from HA-Temsirolimus in PBS was approximately $4 \mathrm{~h}$. The bulk of the drug would therefore be released before the polymer cleared from the target site. However, the sustained release characteristics can be improved by using 3-amino-4methoxy-benzoic acid instead of ADH as a linker to conjugate the drug. This can be explained as HA-Temsirolimus was prepared using an unhindered ester, which allows rapid hydrolysis and release of the drug in water and serum. In comparison, the ester bond in HAL-Rapa is stabilized by the para site methoxy group on the benzene ring that served as a strong electron donating group and reduced the hydrolysis rate. In addition, the ester bond in HA-L-Rapa was more hindered and the drug was in a more rigid condition. These structural configurations provided a more hydrophobic environment than that of HA-Temsirolimus, which may limit access by serum esterase. The release half-life was increased to approximately $36 \mathrm{~h}$ in serum supplemented PBS. This could provide a sustained release of the drug at the targeted tissue and minimize the systemic toxicity by reducing the necessary drug dose and limiting drug non-targeted tissue exposure.

Low molecular weight HA (less than $10 \mathrm{kDa}$ ) was reported to reversibly bind CD44 and is associated with immunogenicity. However, higher molecular weight HA (greater than 30 $\mathrm{kDa}$ ) binds irreversible to CD44 due to the increased multivalent interactions (28). The 
$\mathrm{HA}_{35 \mathrm{k}}$ used in this study has approximately $87 \mathrm{D}$-glucuronic acid repeating units. The $2.6 \%$ $\mathrm{w} / \mathrm{w}$ loading is equivalent to one rapamycin per one polymer chain, so over $98 \%$ of the glucuronic side chains are available for binding CD44.

The in vitro results of the antibody blocking studies showed that the internalization of HAdrug conjugate was inhibited by the H-CAM CD44 inhibitor, which blocked endocytosis and CD44 specific uptake. Since HA-L-Rapa entered the cells through an endocytic pathway, inhibition of this pathway resulted in a reduction of the internalization degree of the polymer drug conjugate. Cellular uptake of the lipid permeable free drug is driven by a concentration gradient. After equilibrium is established, no more drug is able to enter cells, hence inhibition of CD44 receptor did affect free rapamycin uptake by MDA-MB-468 cells. Receptor mediated transport of HA-L-Rapa improved drug delivery in CD44 positive cells and the cytotoxicity was also significantly enhanced. These results also indicated that conjugate of rapamycin does not inhibit the HA-CD44 interaction at the amounts studied; this strategy could be utilized as a novel drug delivery platform for targeted chemotherapy with rapamycin.

This study limited rapamycin to i.p. injection and the conjugate to local s.c. administration. Rapamycin is poorly water soluble and no safe i.v. formulation has been reported. Clinical trials of i.v. rapamycin resulted in injury (swelling and focal lesion) at the injection site, lymphoid atrophy and periarterial edema in the heart, liver (FDA NDA 21-083). Our own previous rat studies demonstrated significant morbidity and a $40 \%$ mortality of i.v. rapamycin in rats (26). Rapamycin cannot be given subcutaneously repeatedly and safely as the free drug. Myckatyn reported skin ulceration in mice administrated $2 \mathrm{mg} / \mathrm{kg}$ rapamycin (one fifth of our dose), and given the ulceration potential of the 4T1.2neu model, this control study was not permitted by institutional animal care guidelines (29). Therefore, in this study, intravenous administration of rapamycin was not investigated.

The pharmacokinetics profile of s.c. HA-L-Rapa was greatly altered compared to the standard i.p. rapamycin formulation. The high value of $\mathrm{V}_{\mathrm{d}}$ of free rapamycin results from its lipophilicity and thus high tissue distribution. The HA conjugate significantly reduced the volume distribution possibly by minimizing nonspecific tissue binding. The increased AUC and slower clearance rate of s.c. HA-L-Rapa are consistent with the sustained release of the drug from the conjugate.

HA targets to CD44 receptors and could specifically bind to CD44 positive cells. HA molecules are uptake by the cells through CD44 receptor-mediated endocytosis followed by lysosomal degradation. The distribution of rapamycin in the HA-L-Rapa treated mice was mainly in the tumor. The significant improvement in exposure drug in target tissues by HAL-Rapa suggested that a lower dose of rapamycin may achieve a therapeutic effect.

In addition, the 4T1 is a highly metastatic cancer cell line (30). At necropsy, lung metastases were observed in 5/5 of the free rapamycin group and only 1/5 of the HA-L-Rapa group. This is consistent with that more drugs were detected in HA-L-Rapa treated animals' lungs. The lung accumulation can be explained by the prevalence of four major HA-binding proteins that potentially contributed to lung pathology regulation: CD44, toll-like receptor 
(TLR4), HA-binding protein 2 (HABP2) and receptor for HA-mediated motility (RHAMM) (31). Meanwhile, HA constitutes the major glycosaminoglycan in lung tissue and it has diverse function in lung homeostasis and pulmonary disease.

HA is cleared from tissues mainly by the lymphatic system due to the presence of lymphatic endothelial hyaluronan receptor, LYVE-1 (32). The expression of LYVE-1 is largely restricted to lymphatic vessels and splenic sinusoidal endothelia cells (33). The LYVE-1 receptor has a $41 \%$ homology to the HA-binding CD44 receptor. This provided an additional HA targeting mechanism. It is consistent with HA-L-Rapa treated mice, where more drug accumulated in the lymph node and the spleen compared to the free drug treatment group.

The breast cancer cell line, 4T1, has an inherent propensity of ulceration (34). Our data illustrated that HA-L-Rapa treatment significantly inhibited tumor growth and diminished the incidence of ulcerated tumor in mammary carcinoma bearing mice. The free rapamycin treatment group showed smaller tumor sizes compared to the non-treatment group. However, the animals were sacrificed due to the presence of hemorrhagic skin ulcers and there was no statically significant survival benefit compared to saline.

Rapamycin is a promising therapeutic agent with both immunosuppressant (mTOR inhibitor) and anti-tumor activities. The immunosuppressant effect of rapamycin comes from the inhibition of $\mathrm{T}$ and $\mathrm{B}$ cell proliferation $(35,36)$, which is the same mechanism of anticancer activity. However, based on currently available evidence, the anti-neoplastic activity is more dominant than that of immunosuppressant effects (37). In our study, we developed a formulation that can target the drug specifically to the tumor and lymphatic tissue via a CD44 interaction. This could further minimize the systemic immunosuppressant activity of rapamycin and augment the anti-cancer effects of the drug.

These results suggest that the rapamycin loaded HA nanoparticle could be used as a potential therapeutic agent for CD44 positive cancers.

\section{Supplementary Material}

Refer to Web version on PubMed Central for supplementary material.

\section{Acknowledgments}

The authors would like to thank Joanna Krise for her assistance performing LC-MS studies.

Funding

This work was funded by the American Cancer Society (RSG-08-133-01-CDD, PI Forrest) and National Institutes of Health (1R01CA173292-01, PI Forrest).

\section{References}

1. Chan JS, Robertson HA, Friesen HG. The purification and characterization of ovine placental lactogen. Endocrinology. 1976; 98(1):65-76. [PubMed: 1248449] 
2. Tzircotis G, Thorne RF, Isacke CM. Chemotaxis towards hyaluronan is dependent on CD44 expression and modulated by cell type variation in CD44-hyaluronan binding. J Cell Sci. 2005; 118(Pt 21):5119-5128. [PubMed: 16234326]

3. Olsson E, Honeth G, Bendahl PO, Saal LH, Gruvberger-Saal S, et al. CD44 isoforms are heterogeneously expressed in breast cancer and correlate with tumor subtypes and cancer stem cell markers. BMC Cancer. 2011; 11:418. [PubMed: 21957977]

4. Misra S, Heldin P, Hascall VC, Karamanos NK, Skandalis SS, et al. Hyaluronan-CD44 interactions as potential targets for cancer therapy. FEBS J. 2011; 278(9):1429-1443. [PubMed: 21362138]

5. Ghosh SC, Neslihan Alpay S, Klostergaard J. CD44: a validated target for improved delivery of cancer therapeutics. Expert Opin Ther Targets. 2012; 16(7):635-650. [PubMed: 22621669]

6. Peer D, Margalit R. Loading mitomycin C inside long circulating hyaluronan targeted nanoliposomes increases its antitumor activity in three mice tumor models. Int J Cancer. 2004; 108(5):780-789. [PubMed: 14696107]

7. Platt VM, Szoka FC Jr. Anticancer therapeutics: targeting macromolecules and nanocarriers to hyaluronan or CD44, a hyaluronan receptor. Mol Pharm. 2008; 5(4):474-486. [PubMed: 18547053]

8. Ferrari M. Cancer nanotechnology: opportunities and challenges. Nat Rev Cancer. 2005; 5(3):161171. [PubMed: 15738981]

9. Li C, Wallace S. Polymer-drug conjugates: recent development in clinical oncology. Adv Drug Deliv Rev. 2008; 60(8):886-898. [PubMed: 18374448]

10. Shakya AK, Nandakumar KS. Applications of polymeric adjuvants in studying autoimmune responses and vaccination against infectious diseases. J R Soc Interface. 2013; 10(79):20120536. [PubMed: 23173193]

11. Liechty WB, Kryscio DR, Slaughter BV, Peppas NA. Polymers for drug delivery systems. Annu Rev Chem Biomol Eng. 2010; 1:149-173. [PubMed: 22432577]

12. Pasut G, Veronese FM. PEG conjugates in clinical development or use as anticancer agents: an overview. Adv Drug Deliv Rev. 2009; 61(13):1177-1188. [PubMed: 19671438]

13. Jain A, Jain SK. PEGylation: an approach for drug delivery. A review. Crit Rev Ther Drug Carrier Syst. 2008; 25(5):403-447. [PubMed: 19062633]

14. Vicent MJ, Dieudonne L, Carbajo RJ, Pineda-Lucena A. Polymer conjugates as therapeutics: future trends, challenges and opportunities. Expert Opin Drug Deliv. 2008; 5(5):593-614. [PubMed: 18491984]

15. Vaidya A, Agarwal A, Jain A, Agrawal RK, Jain SK. Bioconjugation of polymers: a novel platform for targeted drug delivery. Curr Pharm Des. 2011; 17(11):1108-1125. [PubMed: 21434852]

16. Du W, Gerald D, Perruzzi CA, Rodriguez-Waitkus P, Enayati L, et al. Vascular tumors have increased p70 S6-kinase activation and are inhibited by topical rapamycin. Lab Invest. 2013

17. Ge Y, Chen J. Mammalian target of rapamycin (mTOR) signaling network in skeletal myogenesis. J Biol Chem. 2012; 287(52):43928-43935. [PubMed: 23115234]

18. LoRusso PM. Mammalian target of rapamycin as a rational therapeutic target for breast cancer treatment. Oncology. 2013; 84(1):43-56. [PubMed: 23128843]

19. Chong ZZ, Shang YC, Maiese K. Cardiovascular disease and mTOR signaling. Trends Cardiovasc Med. 2011; 21(5):151-155. [PubMed: 22732551]

20. Kamada Y, Funakoshi T, Shintani T, Nagano K, Ohsumi M, et al. Tor-mediated induction of autophagy via an Apg1 protein kinase complex. J Cell Biol. 2000; 150(6):1507-1513. [PubMed: 10995454]

21. Zhao Y, Sun Y. Targeting the mTOR-DEPTOR pathway by CRL E3 ubiquitin ligases: therapeutic application. Neoplasia. 2012; 14(5):360-367. [PubMed: 22745582]

22. Aoki M, Blazek E, Vogt PK. A role of the kinase mTOR in cellular transformation induced by the oncoproteins P3k and Akt. Proc Natl Acad Sci U S A. 2001; 98(1):136-141. [PubMed: 11134523]

23. Gu J, Ruppen ME, Cai P. lipase-catalyzed regioselective esterification of rapamycin: synthesis of temsirolimus (CCI-779). Org Lett. 2005; 7(18):3945-3948. [PubMed: 16119938] 
24. Hioki A, Wakasugi A, Kawano K, Hattori Y, Maitani Y. Development of an in vitro drug release assay of PEGylated liposome using bovine serum albumin and high temperature. Biol Pharm Bull. 2010; 33(9):1466-1470. [PubMed: 20823558]

25. Doane TL, Chuang CH, Hill RJ, Burda C. Nanoparticle zeta -potentials. Acc Chem Res. 2012; 45(3):317-326. [PubMed: 22074988]

26. Yanez JA, Forrest ML, Ohgami Y, Kwon GS, Davies NM. Pharmacometrics and delivery of novel nanoformulated PEG-b-poly(epsilon-caprolactone) micelles of rapamycin. Cancer Chemother Pharmacol. 2008; 61(1):133-144. [PubMed: 17393166]

27. Taryn R, Bagby SC, Shaofeng Duan, Sharadvi Thati, Daniel J, Aires M, Larid Forrest. Impact of Molecular Weight on Lymphatic Drainage of a Biopolymer-Based Imaging Agent. Pharmaceutics. 2012; 4:276-296. [PubMed: 24300232]

28. Wolny PM, Banerji S, Gounou C, Brisson AR, Day AJ, et al. Analysis of CD44-hyaluronan interactions in an artificial membrane system: insights into the distinct binding properties of high and low molecular weight hyaluronan. J Biol Chem. 2010; 285(39):30170-30180. [PubMed: 20663884]

29. Myckatyn TM, Ellis RA, Grand AG, Sen SK, Lowe JB 3rd, et al. The effects of rapamycin in murine peripheral nerve isografts and allografts. Plast Reconstr Surg. 2002; 109(7):2405-2417. [PubMed: 12045568]

30. Hussein O, Tiedemann K, Murshed M, Komarova SV. Rapamycin inhibits osteolysis and improves survival in a model of experimental bone metastases. Cancer Lett. 2012; 314(2):176-184. [PubMed: 22014409]

31. Lennon FE, Singleton PA. Role of hyaluronan and hyaluronan-binding proteins in lung pathobiology. Am J Physiol Lung Cell Mol Physiol. 2011; 301(2):L137-L147. [PubMed: 21571904]

32. Jackson DG. Biology of the lymphatic marker LYVE-1 and applications in research into lymphatic trafficking and lymphangiogenesis. APMIS. 2004; 112(7-8):526-538. [PubMed: 15563314]

33. Leung, K. Molecular Imaging and Contrast Agent Database (MICAD). Bethesda (MD): 2004. Hyaluronan conjugated with IR-783.

34. Wendt MK, Molter J, Flask CA, Schiemann WP. In vivo dual substrate bioluminescent imaging. J Vis Exp. 2011; (56)

35. Dumont FJ, Su Q. Mechanism of action of the immunosuppressant rapamycin. Life Sci. 1996; 58(5):373-395. [PubMed: 8594303]

36. Kay JE, Kromwel L, Doe SE, Denyer M. Inhibition of T and B lymphocyte proliferation by rapamycin. Immunology. 1991; 72(4):544-549. [PubMed: 1709916]

37. Law BK. Rapamycin: an anti-cancer immunosuppressant? Crit Rev Oncol Hematol. 2005; 56(1): 47-60. [PubMed: 16039868] 
A

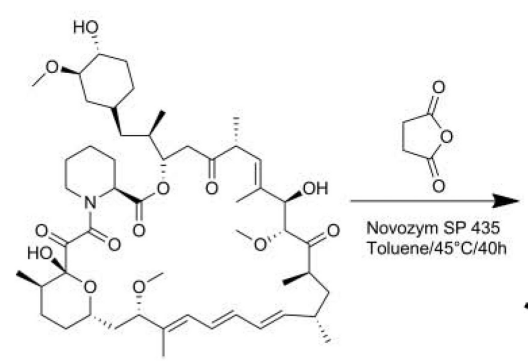

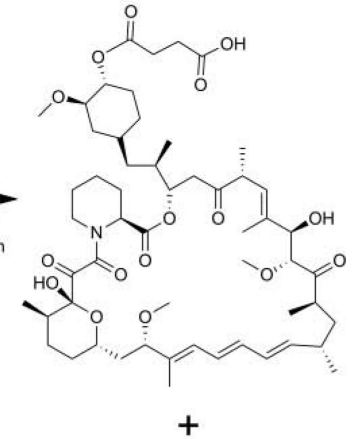

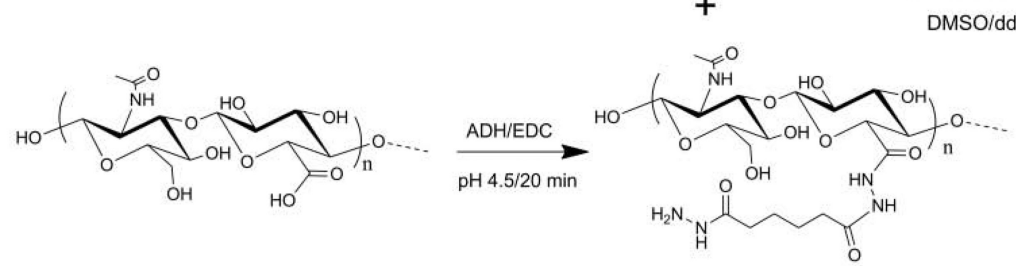
$\underset{\mathrm{DMSO} / \mathrm{ddH} \mathrm{O}_{2} \mathrm{O} / 20^{\circ} \mathrm{C}}{\stackrel{\mathrm{EDC} / \mathrm{HOBt}}{\longrightarrow}}$

B

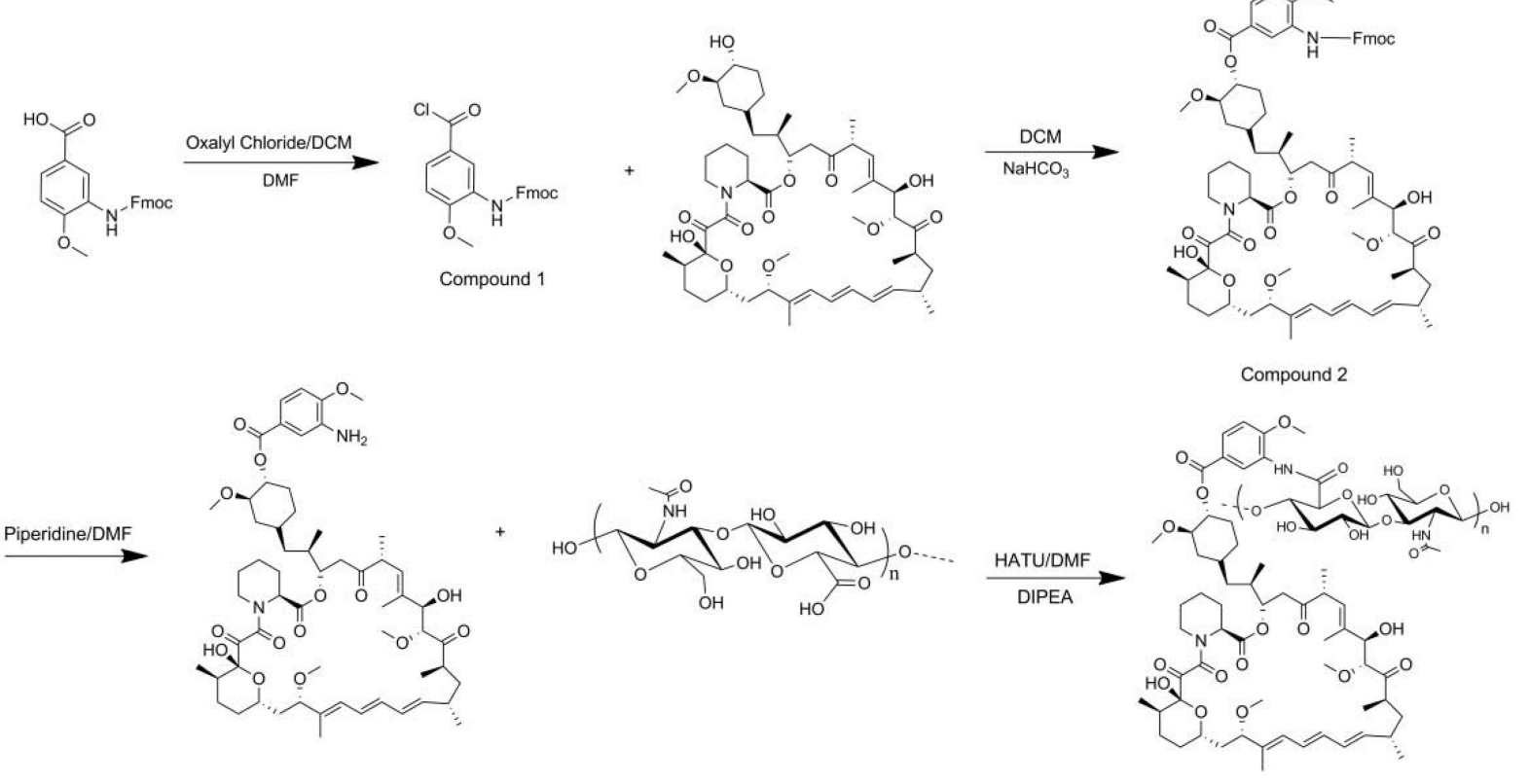

Figure 1.

Synthesis of HA-Temsirolimus (A) and HA-Rapamycin-42-(3'-amino-4'-methoxy) benzoate (HA-L-Rapa) (B). 

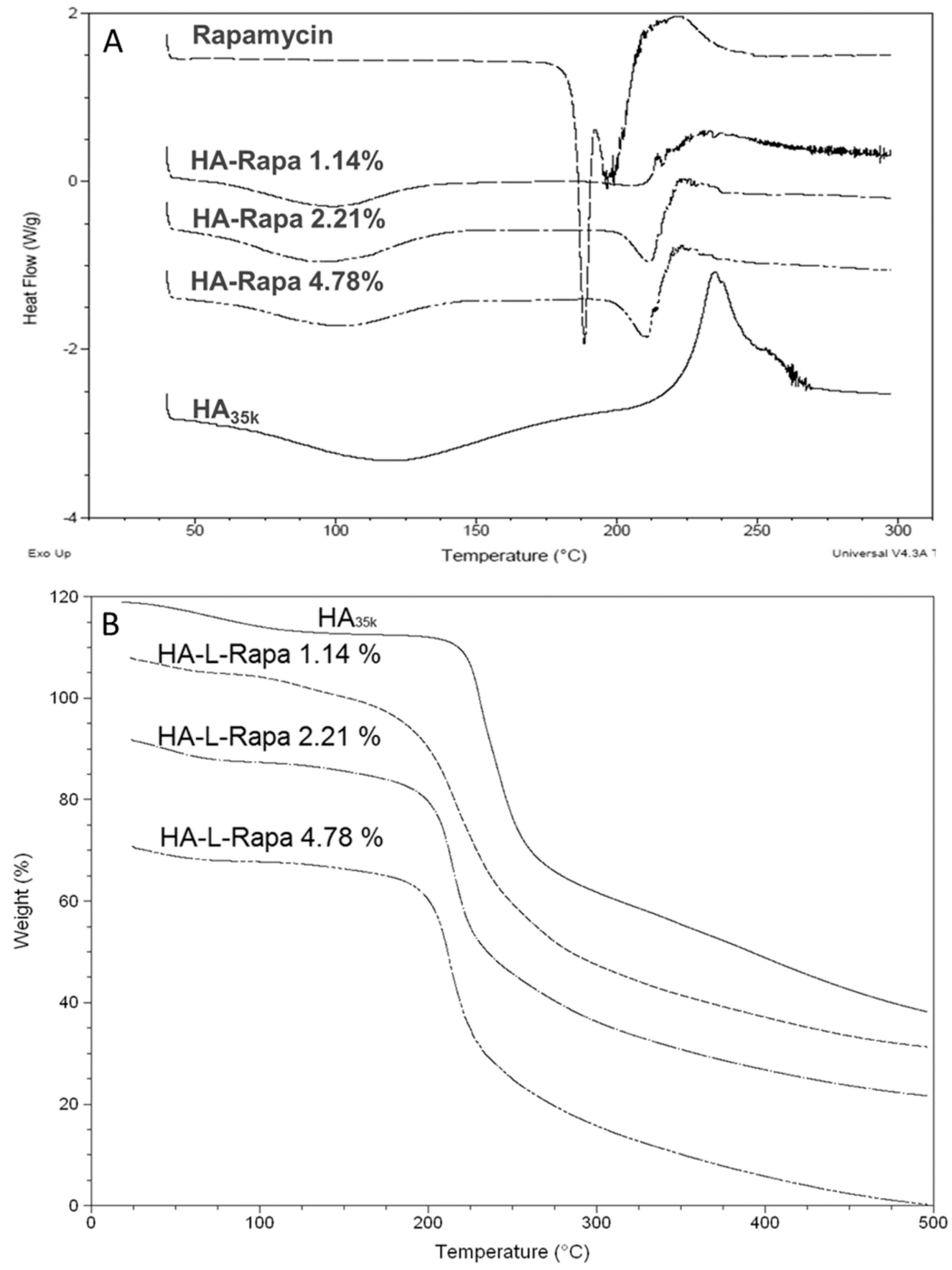

Figure 2.

(A) DSC profiles of rapamycin, $\mathrm{HA}_{35 \mathrm{k}}$ and different loading degree HA-L-Rapa. (B) TGA analysis of $\mathrm{HA}_{35 \mathrm{k}}$ and different loading degree HA-L-Rapa. 

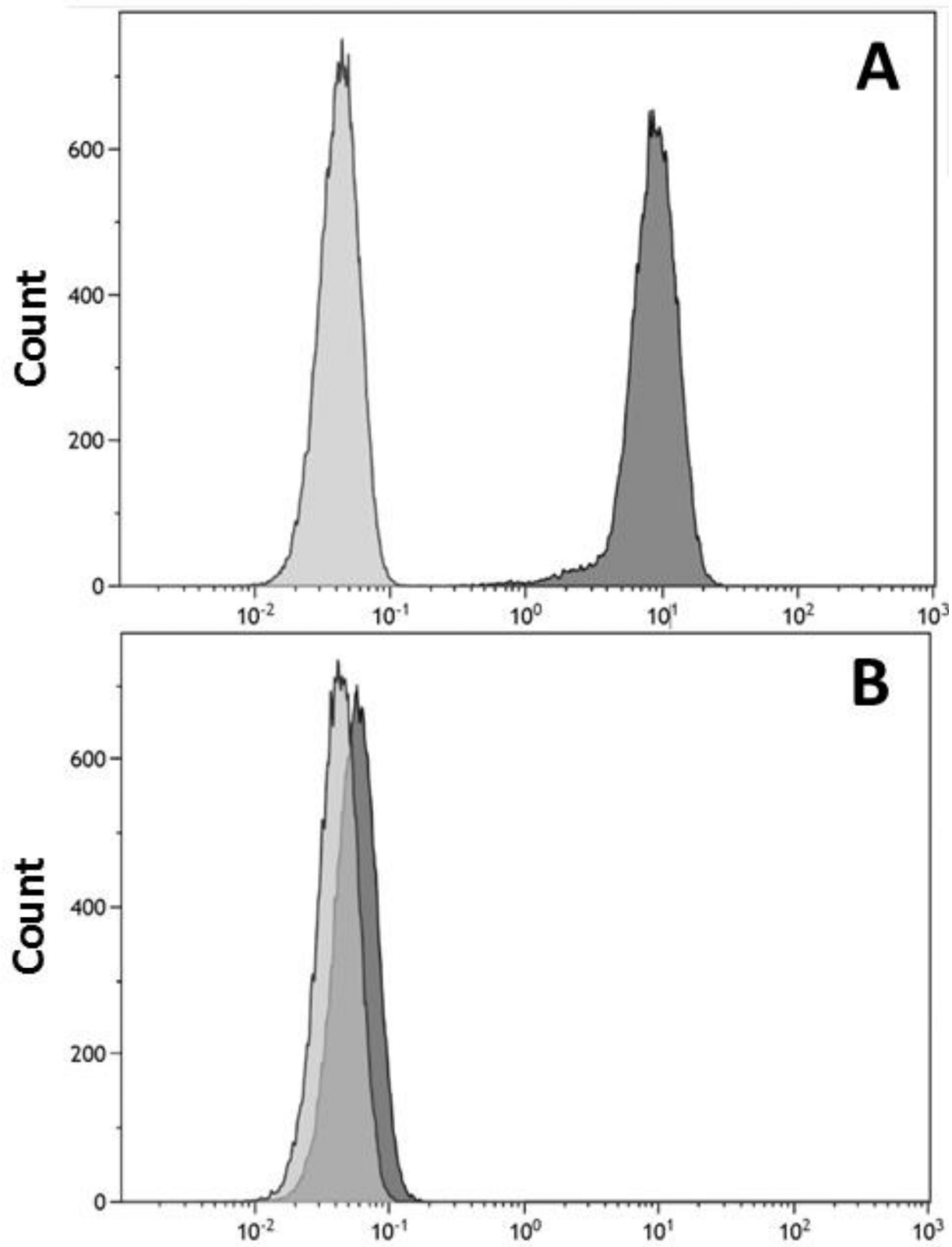

Fluorescence Intensity

Figure 3.

Flow cytometry analysis of available CD44 receptor binding sites on the cell surface. MDAMB-468 (A) and MDA-MB-468 treated with H-CAM (B) were stained with PE anti-CD44 antibody (dark grey) and PE IgGI isotope (light grey). 

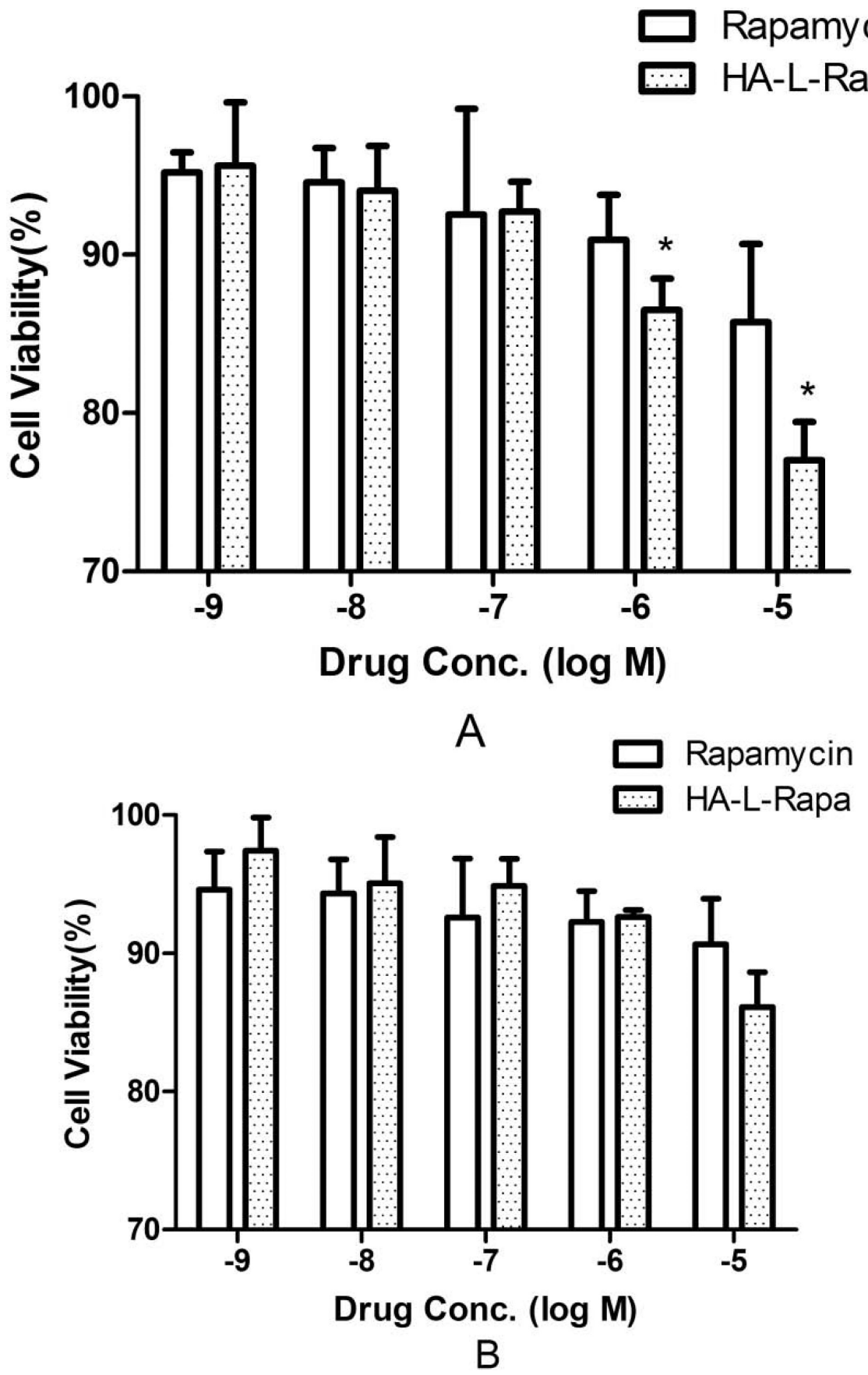

Figure 4.

Cell viability assay of rapamycin and HA-L-Rapa in MDA-MB-468 cells (A) CD44 positive cells and (B) with H-CAM blocking of CD44 (Mean $\pm \mathrm{SD})(*, p<0.05$ ). 


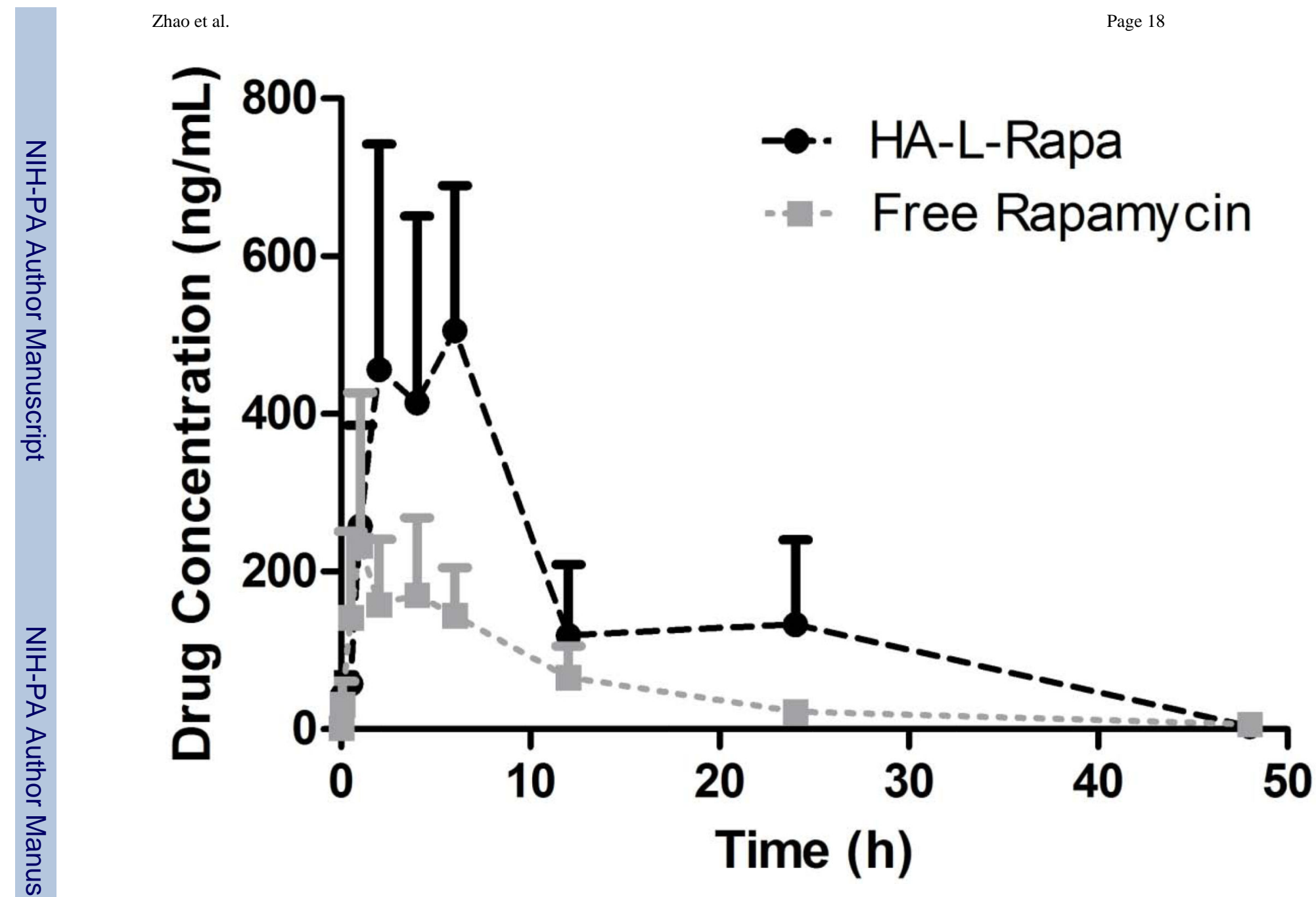

Figure 5.

Plasma rapamycin concentration versus time disposition (Mean $\pm S D, n=3$ ). 


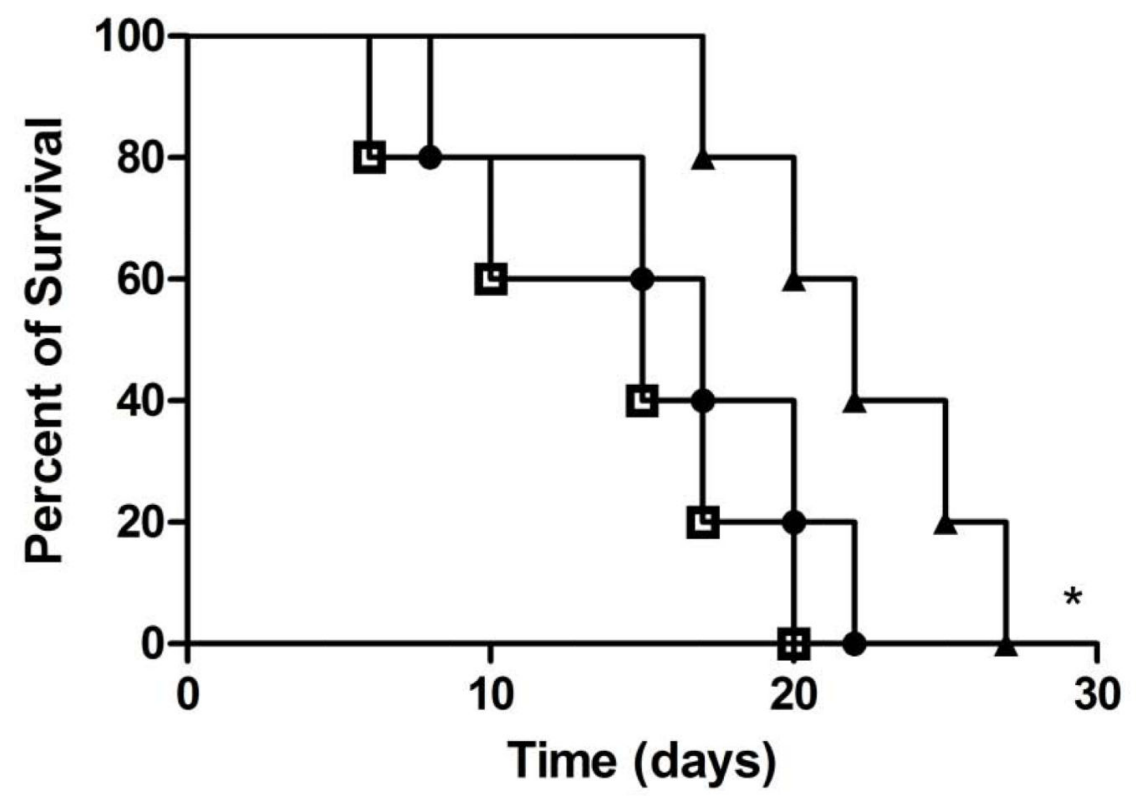

$\rightarrow$ Control

廿 Free Rapamycin

$\leftarrow$ HA-L-Rapa

A

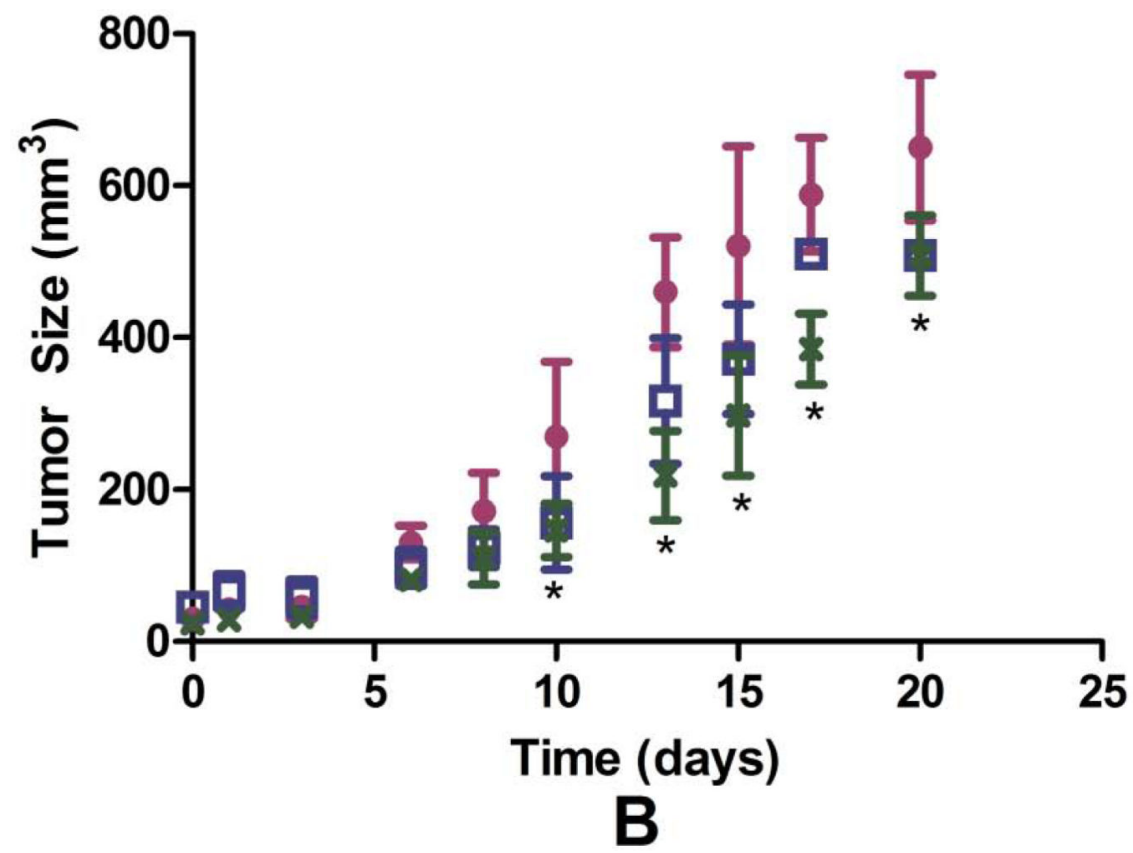

- Control

- Free Rapamycin

× HA-L-Rapa

Figure 6.

HA-L-Rapa significantly improved animal survival (A) and suppressed tumor progression (B) in BALB/c mice with 4T1.2neu breast cancer (Mean $\pm \mathrm{SD})\left(\mathrm{n}=5\right.$; $\left.^{*}, p<0.05\right)$. 


\section{Table 1}

Particle sizes and zeta potentials of HA-L-Rapa with different loading degree

\begin{tabular}{ccc}
\hline Formulations & Size $(\mathbf{n m})$ & Zeta Potential $(\mathbf{m V})$ \\
\hline HA $_{35 \mathrm{k}}$ & $10 \pm 0.045$ & $-77.36 \pm 14.78$ \\
HA-L-Rapa $1.14 \%(\mathrm{w} / \mathrm{w})$ & $9.8 \pm 0.124$ & $-56.15 \pm 8.18$ \\
HA-L-Rapa $2.21 \%(\mathrm{w} / \mathrm{w})$ & $9.4 \pm 0.012$ & $-44.40 \pm 8.11$ \\
HA-L-Rapa 4.78 \% (w/w) & $10.7 \pm 0.014$ & $-13.10 \pm 3.96$ \\
\hline
\end{tabular}

Mean \pm SD 


\section{Table 2}

Pharmacokinetic parameters after i.p. free rapamycin and s.c. HA-L-Rapa.

\begin{tabular}{cccc}
\hline Parameters & Unit & Free Rapamycin i.p. & HA-L-Rapa s.c. \\
\hline $\mathrm{V}_{\mathrm{d}}$ & $\mathrm{L} / \mathrm{kg}$ & $37.68 \pm 15.49$ & $12.88 \pm 5.24^{*}$ \\
$\mathrm{AUC}_{0 \rightarrow \infty}$ & $(\mu \mathrm{g} \cdot \mathrm{h}) / \mathrm{mL}$ & $2.36 \pm 0.46$ & $6.57 \pm 0.92^{* *}$ \\
$\mathrm{Cl}$ & $\mathrm{L} / \mathrm{kg} \cdot \mathrm{h})$ & $4.23 \pm 0.95$ & $2.02 \pm 0.73^{* *}$ \\
$\mathrm{C}_{\max }$ & $\mathrm{ng} / \mathrm{mL}$ & $172.86 \pm 69.06$ & $544.84 \pm 123.56^{*}$ \\
$\mathrm{t}_{1 / 2}$ & $\mathrm{~h}$ & $10.49 \pm 3.76$ & $27.95 \pm 13.33^{*}$ \\
\hline Mean $\pm \mathrm{SD}, \mathrm{n}=3$ & & & \\
$*$ & & & \\
$: p<0.05 ;$ & & & \\
$* *$ & & &
\end{tabular}


Table 3

Mean concentration of rapamycin in mice tissues measured at $12 \mathrm{~h}$ post administration of $10 \mathrm{mg} / \mathrm{kg}$ equivalent rapamycin by i.p. (free rapamycin) and s.c. (HA-L-Rapa) injection.

\begin{tabular}{ccc}
\hline Tissue & Free Rapamycin $(\boldsymbol{\mu g} / \mathrm{g})$ & HA-L-Rapa $(\boldsymbol{\mu g} / \mathrm{g})$ \\
\hline Brain & $107.69 \pm 37.25$ & $195.01 \pm 48.56^{*}$ \\
Kidneys & $469 \pm 27.27$ & $495.04 \pm 349.05$ \\
Tumor & $1237.01 \pm 256.20$ & $1931.84 \pm 195.46^{* *}$ \\
Lymph & $705.28 \pm 115.87$ & $1972.78 \pm 634.80^{* *}$ \\
Heart & $440.73 \pm 81.57$ & $358.88 \pm 110.31$ \\
Liver & $378.72 \pm 40.56$ & $565.56 \pm 54.06^{*}$ \\
Lungs & $617.53 \pm 298.54$ & $1990.00 \pm 634.80^{* *}$ \\
Muscle & $315.56 \pm 154.12$ & $927.64 \pm 453.48^{*}$ \\
Spleen & $183.91 \pm 66.46$ & $1386.31 \pm 342.71^{* *}$ \\
\hline
\end{tabular}

Mean $\pm \mathrm{SD}, \mathrm{n}=5$

${ }^{*}, p<0.05$;

**,$p<0.01$ 